\title{
A CRÔNICA BRASILEIRA E A INTERNET: O ONTEM E O HOJE
}

\author{
LUIS EDUARDO VELOSO GARCIA (UENP) ${ }^{1}$
}

\begin{abstract}
RESUMO: O artigo em questão procurará apresentar um quadro amplo sobre a crônica brasileira contemporânea através de sua recepção dentro da Internet nas três últimas décadas, que compreendem o período de popularização e confirmação dessa tecnologia comunicacional, tanto em seu "ontem" (os primórdios da web e o desenvolvimento de novas percepções entre os anos de 1990 e 2010) quanto o seu "hoje" (o olhar para o tempo presente e as possíveis alterações no decorrer dessas décadas). Inicialmente, será abordado o modo como ocorreu a transposição deste gênero legitimamente fundado no jornal para as plataformas digitais, observando o que chamamos de "ontem" da Internet. Entre os destaques, veremos a concepção da crônica nos jornais e revistas em suas versões onlines, as correntes de e-mails, os populares blogs (e a força das "blônicas") e as redes sociais. Na sequência, intencionamos apresentar como ocorre a recepção do gênero no tempo presente, apontando as alterações que o "hoje" carrega dos primórdios da crônica dentro da Internet, principalmente na passagem da tecnologia de Web 1.0 para Web 2.0. Nosso trabalho, portanto, analisa o quanto um gênero tão popular em nossa literatura como é a crônica pode ter a capacidade de se adaptar da passagem dos suportes impressos para os suportes digitais, continuando a ser extremamente relevante dentro da sociedade brasileira nos dias atuais.
\end{abstract}

PALAVRAS-CHAVE: Crônica brasileira. Literatura contemporânea brasileira. Suportes.

ABSTRACT: The article in question seeks to present a broad picture of the contemporary Brazilian chronicle for its reception on the Internet in the last three decades, period of popularization and confirmation of this communication technology, both in your "yesterday" (the early days of the web and the development of new insights between 1990 and 2010) and in its "today". Initially, I will discuss how the newspaper-based genre was transposed to digital platforms, noting the "yesterday" of the Internet. Among the highlights, will be the conception of the chronicle in newspapers and magazines in their online versions, the currents of e-mails, the popular blogs (and the strength of the "blônicas") and social networks. In the following, we intend to present how the reception of the genre occurs in the present time, pointing out the changes that "today" carries from the early days of the chronicle within the Internet, especially in the transition from Web 1.0 to Web 2.0 technology. Our work, therefore, analyzes the adaptability of such a popular genre in our literature as it is the chronicle in its passage from print to digital media, continuing to be extremely relevant within Brazilian society today.

KEYWORDS: Brazilian chronicle. Brazilian contemporary literature. Suports.

A internet fez a crônica reviver. Antonio Prata

\section{O ONTEM}

A afirmativa destacada como epígrafe, apesar de trazer a força que o espaço da Internet (e seus suportes) terá para o gênero, não condiz com a realidade deste: a crônica nunca precisou ser "revivida", pois, diferentemente de seu suporte clássico que é o jornal impresso (ou as revistas, que acabam sendo o seu desdobramento direto), ela não foi atingida por uma crise de mercado capaz de ameaçar a existência de seu formato.

\footnotetext{
${ }^{1}$ Doutor em Estudos Literários pela Universidade Estadual Paulista (UNESP/Araraquara) e professor do curso de Letras da Universidade Estadual do Norte do Paraná (UENP), Jacarezinho. E-mail: Iuis.garcia@uenp.edu.br
} 


\section{$=$ TRAMA $=$}

Como destaca Joaquim Ferreira dos Santos no livro As Cem Melhores Crônicas Brasileiras (2007), no trecho que se refere às crônicas produzidas após o ano de 2000, "nunca se escreveu tanta crônica como hoje, pois, além dos jornais e revistas que começaram a saga do gênero, criou-se um novo veículo, a internet" (SANTOS, 2007, p.299). Segundo o autor, com a Internet "veio uma multidão de sites e blogs dedicados exclusivamente a pessoas que querem colocar seu cotidiano, seus sonhos e ideias em textos caprichados e bem confessionais" (SANTOS, 2007, p.299).

Na concepção defendida, a crônica consegue espaço nos suportes digitais de maneira natural, em virtude de diversas características que traz em seu formato e que serão pormenorizadas aqui. Entre elas, cita-se o retrato confessional do cotidiano que cerca o próprio cronista (citado por Joaquim Ferreira dos Santos), o tamanho curto do texto, a leveza e a intencionalidade dialógica entre autor e leitor.

Antes de abordar os suportes digitais, é necessário ter a devida percepção temporal da popularização da Internet no Brasil, que apesar de ter chegado em 1988, só ganhou o status de um meio comunicacional popular na segunda metade da década de 1990. Seu trajeto segue com os experimentos dessa nova maneira de comunicação nos espaços da comunidade acadêmica para, na sequência, por meio da exploração comercial de tal tecnologia, a partir de 1994, ganhar um alcance numérico de público bem mais significativo. Nesse contexto, a popularização da Internet ocorre no Brasil de 1994 em diante, e logo nesse início de diálogo com um público consumidor digital, os jornais e revistas começam a experimentar tentativas de versões online para servirem de suporte aos conteúdos criados por esses veículos.

Existem versões diferentes de qual foi o primeiro jornal online do país, com alguns autores apontando para o Jornal do Comércio como o precursor em 1994, e outros para o Jornal do Brasil, em 1995. Esse desencontro é facilmente explicável: o Jornal do Comércio, como cita Luis Fernando da Rocha Pereira (2002), "torna-se o primeiro jornal brasileiro a se aventurar em sistemas digitais [...] através do sistema Gopher, hoje em desuso devido a ascensão da tecnologia de internet (World Wide Web)" (PEREIRA, 2002, online), enquanto o Jornal do Brasil é "o primeiro grande jornal impresso brasileiro a ser vinculado na plataforma web [...] em 28 de maio de 1995" (PEREIRA, 2002, online).

A vinculação do Jornal do Brasil ao suporte da web vai dar maior importância ao seu feito, influenciando outros grandes jornais a trilhar seus caminhos nos anos seguintes, como $O$ Estado de São Paulo, Folha de São Paulo, O Globo, O Estado de Minas, Zero Hora, Diário de Pernambuco e Diário do Nordeste, além de ter sido o primeiro suporte nesse formato de toda a América Latina. Já as revistas online demoraram um pouco mais para se tornarem realidade no país, ganhando seu primeiro veículo apenas em 1997, com a transposição, em junho daquele ano, dos conteúdos da edição semanal da Revista Veja.

Tanto nos jornais quanto nas revistas online, as crônicas já eram vistas nas transposições de conteúdo, uma vez que o seu tamanho reduzido facilitava a passagem para esse suporte, diferentemente de outras reportagens com textos mais extensos. Merecem destaque, aqui, as revistas online que apareceram com o intuito de abrigar produções literárias - e que trazem, obviamente, a crônica como um dos textos bases do espaço -, como O Rascunho (existente desde abril de 2000), Digestivo Cultural (desde setembro de 2000) e Cronópios (desde 2005), e, principalmente, os veículos inteiramente dedicados para o gênero crônica, casos esses das revistas Vida Breve (desde 2009) e RUBEM (desde 2012).

Criado pelos escritores Luís Henrique Pellanda e Rogério Pereira, no dia 2 de novembro de 2009, o site de crônicas Vida Breve publicava, a cada dia da semana, uma dupla fixa de colaboradores, formada por um cronista e um ilustrador. Entre seu quadro de cronistas, 


\section{$=$ TRAMA $=$}

passaram nomes conhecidos, como Fabrício Carpinejar, Henrique Rodrigues, Humberto Werneck, Marcelo Moutinho e Mário Araújo.

A RUBEM é uma revista virtual sobre a crônica criada pelo pesquisador do gênero Henrique Fendrich, e que se encontra ativa até os dias atuais. Além de um quadro de cronistas colaboradores que escrevem todos os dias da semana, a revista conta com resenhas e estudos relacionados à crônica. Dentre eles, destacam-se Alexandre Brandão, Carlos Castelo, Elyandria Silva, Guilherme Tauil, Madô Martins, Mariana Ianelli, Raul Drewnick e Ana Laura Nahas.

O segundo suporte digital na plataforma web no qual a crônica ganhou espaço foram os e-mails, que se tornaram uma ferramenta comunicacional extremamente importante para a época, devido seu funcionamento dinâmico como correio eletrônico, facilitando o diálogo e a troca de informações entre as pessoas em um tempo bem mais veloz do que no correio comum. Logo na primeira década da popularização da Internet no Brasil, entre 1995 e 2005, diversas crônicas se tornavam fenômenos instantâneos, devido à enorme repercussão obtida por compartilhamentos feitos nesse suporte.

Nomes como os de Luis Fernando Veríssimo, Martha Medeiros e Arnaldo Jabor tinham grande imponência para os usuários da Internet, pois suas crônicas chegavam nas caixas de e-mails da maioria dessas pessoas, mesmo sem saberem de onde vinham esses textos. Entre as hipóteses para essa ocorrência, que gerava correntes de e-mails gigantescas das quais não era possível saber quem foi a primeira pessoa a enviar as crônicas que se popularizavam, podese apontar, inicialmente, as características do gênero, como o formato curto, a opção da linguagem leve e acessível, e o diálogo direto com o leitor.

O formato curto, dentro de uma tecnologia em desenvolvimento como era a Internet em seus primórdios no país, é facilmente justificado, afinal, o e-mail não tinha a capacidade de compartilhamento veloz de um texto de grande dimensão física. O mesmo fenômeno atingiu a poesia, de certa forma, e talvez por isso os romances só começaram a ganhar espaço na rede quando suportes de leitura mais consistentes, como o PDF Creator ou as bases do E-book, foram criados.

A linguagem leve e acessível da crônica, juntamente com a intencionalidade de diálogo, aproximou o leitor do suporte digital dessas crônicas, com a diferença que, neste caso, se tratava de um caminho gratuito no qual a leitura não passava exatamente por uma triagem de lucro mercadológico declarado - repassar o texto que lhe agradava por e-mail aos amigos não custava nada a nenhuma das pessoas, a não ser o tempo para a transposição da crônica do primeiro que a trouxe ao e-mail.

O terceiro suporte digital em que a crônica transita com grande força são os espaços dos blogs. Tamanha imponência do gênero dentro dessa estrutura resultou na criação de um neologismo que abarcasse tal relação, base também para um novo tipo de publicação: as "blônicas" - neologismo criado por Nelson Botter para o livro de mesmo título e que carrega a ideia de uma "junção da palavra 'blog' com 'crônicas'” (BOTTER, 2005, p.7).

Nas palavras de Leiza Maria Rosa, em sua dissertação de mestrado A prosa do poeta Gauche: literatura e jornalismo na crônica de Carlos Drummond de Andrade (2015), "com a chegada do século XXI e a geração internet, a crônica ganhou ainda mais espaço, além de impressa passou a ser online e surgiram as blônicas, crônicas escritas para blogs" (ROSA, 2015, p. 22).

Como lembra Antonio Prata, cronista presente também no livro Blônicas, "o que é um blog se não um lugar de crônicas?" (PRATA, 2014, online). Para chegar a essa conclusão, tornase necessário definir, primeiro, o significado da própria palavra "blog". Segundo o Dicionário Eletrônico Houaiss da Língua Portuguesa (2009, s/n), trata-se de uma "página pessoal, atualizada periodicamente, em que os usuários podem trocar experiências, comentários etc., 


\section{$=$ TRAMA $=$}

ger. relacionados com uma determinada área de interesse". No Dicionário Online Caldas Aulete (s/a, online), é definido como uma "página da internet que pode ser criada por qualquer pessoa, com conteúdo livre, ger. pessoal (histórias, ideias, imagens), e que depende de autorização do criador para que os visitantes possam adicionar comentários".

Em ambas as definições, o traço do relato pessoal direcionado ao diálogo com um público leitor fica bem claro, apresentando, desta maneira, a característica primordial que a crônica carrega. Assim como todo texto que busca dialogar com um segmento específico de pessoas, algumas estratégias da linguagem podem ser utilizadas, dentre elas a leveza e o tom coloquial nas escolhas da escrita - mencionadas e bastante recorrentes nos espaços dos blogs.

Em seu texto Blog: Comunicação e escrita intima na internet, Denise Schittine define que esta mídia digital é "uma adaptação virtual de um refúgio que o indivíduo já havia criado anteriormente para aumentar o seu espaço privado: o 'diário íntimo'” (SHITTINE, 2004, p. 60). Um ponto interessante de sua leitura - e, a partir do qual é possível traçar um paralelo com a crônica - é o pressuposto de o blog ser um diário que "deixa de fazer parte da esfera íntima e abre para a esfera pública" (SCHITTINE, 2004, pp. 31-2). Como se sabe, o cronista traz o seu recorte íntimo abertamente para o texto, e quanto mais o seu espaço privado aparece, mais o leitor se vê envolvido no que é narrado.

O esquema do blog que a autora discute também encontra o raciocínio de "comercialização da leitura" que atinge o gênero crônica, pois nas "margens dessa escrita íntima há a intenção de que o leitor adquira a escrita postada na tela digital", pois "há, no mínimo, a ideia de constituir-se escritor fornecendo a escrita como produto" (SHITTINE, 2004, p.23).

É impossível não encontrar similaridades do gênero com as falas da autora para o Blog, como no caso desse tipo de mídia se basear em "uma escrita mais rápida, informal e direta", na qual "aparentemente parecem objetivar o diário íntimo e afastá-lo de sua função confessional", contudo, traz as marcas de um "escrever sobre si próprio, mas ao mesmo tempo comunicando ao outro" (SHITTINE, 2004, p.23), exatamente como se encontra na teoria da crônica.

Os blogs carregam, então, a ideia de "diário", exposição do cotidiano e das experiências pessoais que cercam o "eu" responsável pelo texto, ou na linguagem do espaço digital, aquilo que faz parte do dia a dia do "blogueiro". Tal característica é, como pode-se notar quando se debruça nos textos teóricos mais conhecidos sobre a crônica, um ponto fundamental do gênero.

Observa-se, também, na intencionalidade em dirigir uma mensagem para um público cuja resposta é primordial - incluindo aqui suas reações, que na crônica do jornal impresso poderiam ser medidas de acordo com o no número de cartas recebidas na redação ou nas conversas do cronista com seus interlocutores nas ruas, e que no blog tem a resposta direta dentro dos comentários dos textos publicados -, um pressuposto básico do diálogo construído com seu leitor de que a crônica mercadologicamente se alimenta.

No decorrer de sua história, o blog viu a passagem dos parâmetros definidos para a Internet como Web 1.0 para a Web 2.0, mudança esta que possibilitou para tal tecnologia um nível de circulação de informações, de interação e comunicação entre os usuários desta plataforma antes inimaginável.

Entendida como uma nova "lógica da participação", segundo a qual vê-se que o "conteúdo deixa de ser produzido por poucos portais e veículos de comunicação e passa a ser produzido e consumido por diversos usuários ao redor do mundo, cada qual compartilhando experiências, conversas, desejos e anseios do seu cotidiano" (RIBEIRO; AYRES, 2014, p.201), a Web 2.0 deu ainda mais possibilidades para que a crônica pudesse ser produzida no meio digital. Isto é, a base do pensamento do cronista, que era trazer em seus textos as "conversas, desejos e anseios do seu cotidiano", tão afirmada na teoria conhecida do gênero, achou a 


\section{$=$ TRAMA $=$}

possibilidade de ser produzida para um grande público sem os limites impostos pelos grandes veículos de comunicação impressos, principalmente os limites mercadológicos e ideológicos.

Entre as possibilidades abertas pela Web 2.0, as redes sociais, principalmente o Facebook, tornaram-se os suportes digitais em que melhor se observa a produção da crônica na atualidade. Minha definição de rede social deriva do pensamento de Danah M. Boyde e Nicole B. Ellison, expresso no trabalho "Social network sites: definitions, history, and scholarship":

Serviços de web que permitem aos usuários: (1) construir um perfil público ou semi-público dentro de um sistema conectado, (2) articular uma lista de outros usuários com os quais eles compartilham uma conexão e (3) ver e se mover pela sua lista de conexões e pela dos outros usuários dentro do sistema (BOYD; ELLISON, 2007. p. 2).

Para tanto, a presente reflexão se concentrará na rede social do Facebook, não só por ser a rede social mais significativa do momento atual (em 2017 atingiu o impressionante número de 2 bilhões de usuários), mas por ter sua base de linguagem inteiramente construída em modelos comunicacionais encontrados na crônica. Obviamente, não se pretende afirmar que o seu criador Mark Zuckerberg tinha a intenção de propor um suporte ideal para a crônica, pois se trataria de uma afirmação leviana, mas é possível refletir, a partir de uma análise voltada ao princípio de construção das relações interpessoais dessa rede social, sobre alguns paralelos muito fortes com a prática do gênero em questão.

Assim como nos blogs, observam-se no Facebook as regras básicas de interações comunicacionais humanas por meio do compartilhamento de experiências pessoais, informações e notícias direcionadas diretamente à um possível público leitor virtual. A grande diferença aqui é o tamanho do alcance que essa rede social gera quanto o modo ainda mais dinâmico de diálogo com tal leitor, com possibilidades de respostas mais diretas e velozes.

A própria pergunta que o Facebook usa como chave para provocar a reação textual pelas postagens de seus participantes, instigando a ação comunicacional com os possíveis leitores, colabora para uma hipótese de leitura junto à crônica: "No que você está pensando?". Na crônica têm-se o olhar subjetivo do cronista para os eventos do "miúdo do cotidiano" (como nos lembra Davi Arrigucci Jr. em "Fragmentos Sobre a Crônica"), do recorte local que o cerca na "vida ao rés-do chão" (na expressão cunhada por Antonio Candido), e claramente é encontrado esse exercício na perspectiva do "que está pensando" tal autor - e não somente para sua vida íntima, mas daquilo que ele deseja transmitir como diálogo direto ao público.

Se o público do jornal era uma construção clara desse diálogo entre cronista e leitor, dentro do espaço da rede social o recorte se propõe aos "amigos" da timeline de quem escreve, elevando a prática cronística a qualquer pessoa que desejar responder a dinâmica provocada pela frase "no que você está pensando?", afinal, esta resposta trará o recorte subjetivo para questões diretamente relacionadas ao seu cotidiano. Por isso, podemos afirmar que o princípio de postagem do Facebook parte de um movimento semelhante ao da crônica.

Outra reflexão que encontra paralelos entre a linguagem do Facebook e a crônica é o modo de expor o próprio sujeito nos textos. Como pode-se supor, o sujeito que se coloca na crônica tem uma proximidade maior com a ideia da autoficção do que com a autobiografia em si, pois ao partir de dados da realidade que o cerca (que pode ser, inclusive, inventada, como já se viu em diversos relatos de cronistas), o escritor estetiza sua versão textual com moldes do gênero, desde a linguagem leve até uma apresentação do sujeito que "conversa" com seu leitor, buscando sempre uma maneira que não quebre o diálogo. Se a autobiografia (e, também, o 


\section{$=$ TRAMA $=$}

diário) é uma fala para si próprio, a autoficção é um "si próprio" direcionado para a fala com o outro - nesse suporte representado como o leitor da timeline.

A ideia da "encenação de si" - que é tão bem elucidada em relação à autoficção nas reflexões de Karl Erik Shollhammer em seu livro Ficção Brasileira Contemporânea (2010), mais especificamente no capítulo "O Sujeito em Cena" - carrega este princípio vindo do léxico teatral, cuja intencionalidade dos autores-atores de obras autoficcionais se apresentam por meio de uma encenação devidamente direcionada para o espectador-leitor. Como discorre o autor, "o miolo do real é o sujeito, e a lição serve para uma espécie de encenação de si" (SHOLLHAMMER, 2010, p. 108).

Se na autoficção esse jogo de "encenação de si" colabora para "a finalidade de semear dúvida a respeito da sinceridade enunciativa do 'eu' narrativo" (SHOLLHAMMER, 2010, p. 108) e o aceite do leitor pelo "jogo de espelhos entre o 'eu' que fala e o 'eu' falado" (SHOLLHAMMER, 2010, p. 108), a proposta que a crônica carrega por esses caminhos é outra: ela não quer a confusão do leitor, mas sim a sua proximidade. Tal conexão é construída tanto pelas ideias básicas da verossimilhança do autor com o espaço que o cerca (espaço, muitas vezes, em que vive o leitor em questão), quanto por sua intenção de construir um diálogo que não ocorreria se o cronista explorasse o jogo autoficcional em um nível igual ao que é construído pelos romancistas desse estilo.

No Facebook, assim como na crônica desde sua origem no jornal, o sujeito que se apresenta dentro da timeline tem muito desse jogo de encenação, afinal, ele só existe naquele espaço para dialogar com o outro que o lê. Se não houver leitores, como pode-se supor, sua existência textual nessa rede social torna-se praticamente nula. Por esse princípio, a hipótese de que todo autor que se coloca dialogando com a timeline construída por meio de seu perfil do Facebook é, também, um potencial cronista, ganha um sentido possível, ainda mais quando observamos tantos cronistas que têm em seus perfis dessa rede social um número gigantesco de seguidores que dialogam diretamente com eles, como ocorre com Xico Sá, Tati Bernardi, Gregório Duvivier, Fabrício Carpinejar, entre outros.

\section{O HOJE}

Talvez algum dia, nas próximas décadas, você esbarre nessa crônica, pela internet. Antônio Prata

Isso posto, torna-se necessário uma reflexão acerca do local em que a crônica se encontra reproduzida nos suportes digitais da Internet no tempo presente, a começar pelo aprofundamento das ideias sobre a produção do gênero nos jornais online. Em segundo momento, pensar a ponte estabelecida entre esse primeiro suporte e as redes sociais, pois as duas mídias digitais se encontram no jogo mercadológico - e, consequentemente, comunicacional - dessa tecnologia na contemporaneidade.

Retomando o que já foi dito a respeito dos três suportes impressos conhecidos da crônica - jornal, revista e livro -, a tentativa de sobrevivência deles na atualidade depende, de certa maneira, da adaptação de suas versões impressas aos modelos das mídias digitais. Nesta passagem de plataformas, a crônica se mantém como um produto fundamental, publicada tanto nas versões impressas, que ainda existem, quanto nas digitais.

Por sua enorme importância no gênero, o jornal merece um destaque especial nessa discussão. Acerca disso, Caio Tulio Costa (2014) elenca algumas possíveis causas para a queda vertiginosa do jornal impresso como produto, apontando para o mesmo processo em que a Internet ganha a frente desse espaço mercadológico. Segundo o autor, "desde o fim do século XX, outros atores surgiram", entre eles "novas empresas de telecomunicações, 


\section{$=$ TRAMA $=$}

poderosos buscadores (como o Google), grande número de portais e arrojados gadgets (smartphones, tablets), além das onipresentes redes sociais (Facebook, Foursquare, Instagram, Twitter, YouTube)" (COSTA, 2014, p.84).

Outra possibilidade levantada pelo autor é que "o público consumidor assumiu ares de protagonista", tornando-se "produtor e distribuidor de informação" (COSTA, 2014, p.84). Em suas palavras, "com a emergência da interação em tempo real em rede, o jornalista - e, portanto, o próprio jornalismo - perdeu completamente o papel que ele se atribuía de 'quarto poder'. Hoje qualquer indivíduo ou instituição tem poder de mídia no ecossistema digital" (COSTA, 2014, p. 85).

A expressão "quarto poder" usada pelo autor se refere a uma conotação dada a Mídia na qual sua força como meio de comunicação de massa pode ser equiparada aos outros Três Poderes nomeados de um Estado Democrático - o Legislativo, Executivo e Judiciário

Um exemplo de que, talvez, o público consumidor do jornal hoje em dia esteja realmente nos limites do ciberespaço, são os números levantados em 2017 em uma pesquisa do Instituto Verificador de Comunicação (IVC). Segundo essa pesquisa, a circulação digital paga de jornais subiu $27 \%$ no ano de 2015 , em comparação com 2014 , enquanto a impressa caiu $13 \%$.

A revista seguiu o mesmo processo do jornal na perda de consumidores da sua versão impressa, e dentre as tentativas de sobrevivência, o processo de adaptação às mídias digitais se apresenta como única saída possível - sendo que alguns veículos passam a ser publicados somente no suporte digital nos dias atuais.

No caso dos livros, a contemporaneidade nos dá a possibilidade de acessá-los por meio de plataformas comercializadas para a leitura de e-books, sendo que as marcas mais conhecidas no Brasil são o Kindle, o Lev e o Kobo. Por se tratarem, muitas vezes, de obras de autores com certa popularidade e um público leitor considerável, os livros de crônicas acabam sendo lançados hoje em dia diretamente nos formatos impressos e digitais.

Se os suportes impressos precisaram de um enorme esforço para a transposição de suas plataformas para os suportes digitais, torna-se imprescindível o olhar para os suportes das páginas digitais em que a crônica é reproduzida hoje em dia, cabendo a leitura atenta que o ciberespaço exige.

Entre os sites levantados sobre essa prática, e que trazem a crônica como um dos textos literários ali encontrados, torna-se importante a lembrança dos portais $O$ Rascunho, Digestivo Cultural, Cronópios, Vida Breve e RUBEM, dos quais ainda se encontram alguns em plena atividade. Os blogs, que antes se mostravam como suportes fundamentais para o gênero, perderam sua relevância no tempo presente. Um dos possíveis motivos para tal ocorrência corresponde ao papel exercido pelas redes sociais após o advento da Web 2.0, que conseguem complementar todos os ideais que eram vistos em seu formato com uma participação e diálogo muito mais vivo e dinâmico entre o leitor-consumidor do texto e o próprio autor.

Pouquíssimos cronistas ainda insistem nesse formato, já que ele não demonstra mais a mesma popularidade que carregava nos primeiros anos da Internet, e também por não ter evoluído sua estrutura técnica, ponto esse que pesa bastante quando o assunto é tecnologia para auxiliar a comunicação humana nos meios digitais. No entanto, o caminho dos suportes digitais que exige mais atenção analítica atualmente é a maneira como a crônica é publicada e consumida na rede social do Facebook, rede essa em que ela pode ser transposta completamente, além de facilitar muito o diálogo direto entre o cronista e seu público alvo.

Nas demais redes sociais de grande alcance no país (Twitter, Whatsapp, Instagram, Youtube, etc.), pode-se observar um espaço competente de publicidade para o gênero, não por sua reprodução direta como almejam os suportes digitais, mas sim com links e divulgações para chegar a publicação original em que se encontra. Dessa forma, a partir de um link no 


\section{$=$ TRAMA $=$}

Twitter pode-se acessar uma crônica na página da web, que reproduz sua versão digital de jornal ou revista; ou assistir no Youtube a um vídeo de divulgação de um livro lançado do gênero (sendo sua versão impressa ou e-book); e, até mesmo acessar por meio do WhatsApp uma postagem de uma crônica dentro do Facebook. Essa rede social se torna, portanto, a única na qual o gênero pode ser divulgado e, também, produzido integralmente, pois cumpre a função de suporte digital da maneira mais completa.

A própria lógica de consumo da crônica dentro do Facebook é diferenciada, pois, muitas vezes, não segue um caminho que seria desejado pelos princípios mercadológicos que tanto marcaram esse texto. Aliás, na maioria das leituras feitas nesse suporte digital o leitor nem paga por tal consumo, o que não the impede de ser o responsável pela impulsão, discussão e significação social do trabalho do cronista dos dias atuais.

Para colaborar com uma possível sistematização teórica do caminho de produção e diálogo com o público consumidor da crônica contemporânea no Facebook, propõe-se uma reflexão acerca das seguintes fases cumpridas por uma crônica publicada:

1. A crônica inicia seu caminho após ser publicada no jornal de origem, tanto em meio impresso quanto em sua versão digital;

2. A versão impressa, como foi demonstrado, tem um número de venda cada vez menor atualmente, não sendo possível apontá-la como responsável pelo enorme alcance que têm os textos dos cronistas contemporâneos;

3. A versão digital, publicada no site do jornal, tem acesso restrito para quem não é assinante, o que não impede em nada a leitura do conteúdo, pois uma busca mínima no Google perguntando "como desbloqueia conteúdo restrito de jornal digital" dá resultados extremamente válidos e fáceis de usar para qualquer pessoa, não necessitando de pleno domínio de informática do leitor;

4. Conforme a relevância do tema (calculada pelas pautas que a rede social em questão se alimenta, relativizadas por temas que estejam em voga, não necessariamente para a nossa sociedade como um todo, mas sim para os usuários da rede social, a comunidade virtual que abrange aquele recorte social) que está sendo discutido dentro da crônica do autor, esse tema gerará discussão no espaço das redes sociais;

5. Para que o processo de repercussão aconteça, as páginas que discutem as temáticas colocadas em pauta na crônica irão copiá-la em seus espaços digitais, sem nenhuma preocupação em cumprir qualquer princípio de direitos autorais com o material em questão, seja do autor ou do jornal em que a obra foi publicada;

6. Logo no mesmo dia é possível encontrar na timeline do Facebook diversas cópias na íntegra da crônica, sem nenhuma relação com o jornal em que ela nasceu;

7. Tais cópias acabam sendo incessantemente compartilhadas (conforme a lógica da relevância temática que a crônica carrega ao público dessa comunidade virtual) por um número significativo de usuários; 


\section{$=$ TRAMA $=$}

8. Entre os usuários que colaboram com a impulsão da crônica em questão, podemos definir dois padrões: os que compartilham para concordar com o ponto de vista do cronista e os que compartilham para atacar o ponto de vista do cronista;

9. O mesmo padrão dos que compartilham por serem a favor e os que compartilham por serem contra repete-se nas páginas que copiam a crônica, refletindo claramente seus posicionamentos políticos;

10. Por último, o perfil do autor em questão (seja por sua página oficial ou por seu perfil pessoal dentro dessa rede social) é usado como espaço em que esses leitores se dirigem para fazer elogios ou ofensas, ambos de maneira pública, gerando outras grandes discussões dentro daquele espaço. Se o cronista se posicionar diante dessas discussões em sua página, elas se tornarão ainda mais relevantes e maiores para a comunidade virtual a qual pertence. Esse princípio gera relevância e movimentação no perfil do autor, aumentando ou diminuindo o número de likes.

O que se vê no trajeto apresentado é uma lógica que leva em consideração não os números de vendagem ou cartas recebidas pelo cronista no jornal, mas sim sua relevância dentro da comunidade virtual a qual se dirige, pois, a marca do veículo, indiretamente, estará em destaque junto a ele.

Uma boa forma de ilustrar essa lógica pode ser vista na crônica de Gregório Duvivier intitulada "Lambança do Datafolha revela Folha mais conservadora do que capitalista", que se encontra no livro Caviar é uma ova (2016) e foi publicada, primeiramente, com o título de "Errar é humano, manipular é escroto", no jornal Folha de São Paulo do dia 25/07/2016. No texto em questão, o autor tece críticas diretas ao jornal em que escreve. No texto em questão, Duvivier discorre sobre sua discordância política em relação à Folha de São Paulo, conhecida por posicionamentos mais conservadores de direita, enquanto se coloca como alguém claramente de esquerda.

Na leitura polêmica - mas perspicaz - da lógica de mercado que o mantém dentro de um jornal que não representa a mesma opinião que a sua, o cronista aponta para a diferença do público que pauta o "consumo" do texto hoje em dia: "O que movia a máquina era a vendagem, hoje é o clique" (DUVIVIER, 2016, p.172).

Assim, um autor que gere mais discussões nas redes sociais - os famosos cliques citados - torna-se uma peça valiosa para o jornal, não importando se representa alguma bandeira política contrária as suas pautas fixas, afinal, o que vale é que ele deixa a marca da empresa em destaque, gerando marketing indireto para ela também. No caso da Folha de São Paulo, como ironiza Duvivier, a lógica é clara: "a Folha não é conservadora, ela é capitalista" (DUVIVIER, 2016, p.172).

A lógica do clique supera a lógica de vendagem do suporte impresso nos dias atuais. $\mathrm{O}$ cronista em questão sabe bem disso e também o quanto seu diálogo com o espaço digital o protege, para manter livremente o modo de pensar o cotidiano que o cerca por meio da crônica (lembrando que esse cotidiano tem na comunidade virtual um novo espaço de socialização e troca comunicacional).

A mesma regra vale para outros posicionamentos políticos diferentes ao dele, pois nas fases que uma crônica contemporânea atravessa de sua publicação no jornal até o Facebook, quanto maior repercussão dentro da dualidade política que move os discursos simplificados das redes sociais, melhor para o autor ganhar visibilidade, ou como ele mesmo diz, "por isso estou 


\section{$=$ TRAMA $=$}

aqui: porque (vai entender) dou clique. Por isso, também, a direita mais hidrófoba está neste jornal: porque (vai entender) dá clique. Faz sentido, não faz?" (DUVIVIER, 2016, p.172).

Conforme procurou-se demonstrar, os suportes que ignorarem uma possibilidade de aproximação com o virtual podem estar fadados à morte, pois não existe mais lógica econômica que não seja atingida pela Internet, e sendo a crônica literatura e, também, produto com intencionalidade de venda que seus suportes sempre exigiram, quem a pratica necessita desse entendimento para que seus textos ganhem força na época atual.

\section{REFERÊNCIAS}

ARRIGUCCI Jr., D. 1987. Fragmentos sobre a crônica. IN: Enigma e Comentário. São Paulo:

Companhia das Letras, 1987, p. 51-66.

ARRUDA, Felipe. 20 Anos de Internet no Brasil: aonde chegamos? Portal Tecmundo. Disponível em: http://www.tecmundo.com.br/internet/8949-20-anos-de-internet-nobrasil-aonde-chegamos-.htm. Acesso em: 10 nov. 2019.

BOTTER, Nelson. Apresentação. In: (Org.). Blônicas. São Paulo: Jaboticaba, 2005.

BOYD, Danah; ELLISON, Nicole. Social network sites: definitions, history, and scholarship. Journal of Computer-Mediated Communication, 13 (1), 11, 2007.

BRUNNER, Diogo. Autofiç̧ão: quais os limites do eu. Disponível em:

http://lounge.obviousmag.org/ao_sul_de_lugar_nenhum/2013/10/autoficcao-quais-os-limites-do-eu.html. Acesso em: 10 nov. 2019

CALDAS, Aulete. Dicionário Contemporâneo da Língua Portuguesa: Dicionário Caldas Aulete, versão online. Disponível em: http://www.aulete.com.br/ acesso em: 10 nov. 2019.

CANDIDO, Antonio. A vida ao rés-do-chão. In: Candido, Antonio (et al). A crônica: o gênero, sua fixação e suas transformações no Brasil. Campinas: Ed. Unicamp; Rio de Janeiro: Fundação Casa de Rui Barbosa, 1992. p. 13-22.

COSTA, Caio Tulio. Rumos do Jornalismo. Pesquisa FAPESP, n² 220, junho de 2014, p. 82-85.

DUVIVIER, Gregorio. Caviar é uma Ova. São Paulo: Companhia das Letras, 2016.

HOUAISS, Instituto Antonio. Dicionário Eletrônico Houaiss da Língua Portuguesa: Versão 3. 0. São Paulo: Objetiva, 2009.

INSTITUTO VERIFICADOR DE COMUNICAÇÃO (IVC). Dados da Pesquisa. Disponível em: https://www.ivcbrasil.org.br/\#/home . Acesso em: 10 nov. 2019.

PEREIRA, Luis Fernando da Rocha. O adiantado do minuto: a Internet e os novos rumos do Jornalismo. Disponível em: http://www.bocc.ubi.pt/pag/pereira-luis-novos-rumos-do-jornalismo.pdf Acesso em: 10 nov. 2019.

PRATA, Antonio. A Internet fez a crônica reviver... Folha de São Paulo, São Paulo, online, 9 set. 2014. RIBEIRO, José Carlos; AYRES, Marcel. Breves comentários sobre a Análise de Conversações em sites. PORTO, Cristiane; SANTOS, Edméa (Orgs.). Facebook e educação: publicar, curtir, compartilhar. Campina Grande: Eduepb, 2014

SANTOS, Joaquim Ferreira dos. Introdução. In: (Org.). As cem melhores Crônicas Brasileiras. Rio

de Janeiro: Objetiva, 2007

SCHITTINE, Denise. Blog: Comunicação e escrita íntima na Internet. Rio de Janeiro: Civilização Brasileira, 2004.

SCHOLLHAMMER, K.E. Ficção Brasileira Contemporânea. Rio de Janeiro: Civilização Brasileira, 2010.

Recebido em 10-01-2020

Aceito em 04-05-2020 